Macedonian Pharmaceutical Bulletin, 66 (Suppl 1) 3 - 4 (2020)

Online ISSN 1857 - 8969

UDC: 577.1:61 616-074

DOI: 10.33320/maced.pharm.bull.2020.66.03.001

Short communication

\title{
The Medical Biochemistry and Laboratory Medicine are important diagnostic branches
}

\author{
Nada Majkić-Singh \\ Society of Medical Biochemists of Serbia, 11000 Belgrade, Serbia
}

\section{Introduction}

Medical biochemistry is the usual name for clinical biochemistry or clinical chemistry in Serbia, and medical biochemist is the official name for the clinical chemist (or clinical biochemist). This is the largest sub-discipline of the laboratory medicine in Serbia. It includes all aspects of clinical chemistry, and also laboratory hematology with coagulation, immunology, etc. Medical biochemistry laboratories in Serbia and medical biochemists as a profession are part of Health Care System and their activities are regulated through the Health Care Law and rules issued by the Chamber of Medical Biochemists of Serbia.

Since school-year 2006/2007 as a result of the Decision of the University Senate in Belgrade the Faculty of Pharmacy has been offering courses according to new curricula and syllabuses, entirely in the line with the Bologna Declaration, i.e. with the study programme of the EU member-states. The Bologna process represents a standardization of the European higher education area thus enabling compatibility and comparability of different study programme mobility of students and teaching staff as well as the possibility of degree recognition.

One of important attainments of the Bologna process is the European Credit Transfer System (ECTS). In order to meet the requirements of the National Accreditation Committee the adjusted study syllabuses have been adopted for the integrated graduate five year studies of Pharmacy and Pharmacy-Medical Biochemistry (Majkić-Singh, 2010).

Creative work and research in medical biochemistry requires broad formal training in basic natural sciences and medicine and extensive laboratory experience. During the studies PharmacyMedical Biochemistry, medical biochemist is qualifying for work in clinical-biochemical, toxicological and sanitary laboratory dealing with medical biochemical, toxicological and sanitary practice. In the course of education, a student is expected to acquire knowledge on: human organism, disease, role of biochemical laboratory in diagnostics and health care system. In the course of the study, a student is expected to acquire abilities and skills for: laboratory work, quality control that assures continuous process of checking and assessment measuring values to obtain reliable result and medicinally relevant information, handling with instruments and equipments, protection of laboratory staff and safe handling with chemicals and biological materials as well as pharmaceutical/ medicinal waste (Majkić-Singh, 2011; Study Programme).

\section{EFLM syllabus for postgraduate education and training for Specialist in Laboratory Medicine}

Although laboratory medicine practice varies across the European Union's (EU) member states, the extent of overlap in scope is such that a common syllabus describing the education and training associated with high-

$\overline{\text { *singh@eunet.rs }}$ 
quality, specialist practice can be identified. In turn, such a syllabus can help define the common set of skills, knowledge and competence in a Common Training Framework (CTF) for nonmedical Specialists in Laboratory Medicine under EU Directive 2013/55/ EU (The recognition of Professional Qualifications). In meeting the requirements of the directive's CTF patient safety is particularly enhanced when specialists seek to capitalize on opportunities for free professional migration across EU borders. In updating the fourth syllabus, the fifth expands on individual discipline requirements, new analytical techniques and use of statistics. An outline structure for a training programme is proposed together with expected responsibilities of trainees and trainers; reference is provided to a trainee's log book. In updating the syllabus, it continues to support national programs and the aims of EU Directive 2013/55/EU in providing safeguards to professional mobility across European borders at a time when the demand for highly qualified professionals is increasing in the face of a disparity in their distribution across Europe. In support of achieving a CTF, the syllabus represents EFLM's position statement for the education and training that underpins the framework (Jassam et al., 2018)

A syllabus is a plan showing the subjects and/or books to be studied in a particular course, especially a course that leads to an examination. When there is substantial similarity between syllabi, it opens the opportunity to harmonise common principles of education and training. The transposition of European Union (EU) Directive 2013/55/EC (The Recognition of Professional Qualifications) into member states' national laws in January 2016 reflected that although there is demand for highly qualified individuals across the Union, there is also disparity in their distribution. In creating a mechanism for mutual recognition of professional qualifications, the directive

- supports individuals seeking unhindered free professional movement across EU borders,

- helps catalyze a more equitable distribution of human resource and services across the Union,

- can obviate the need for member states to impose "compensation measures" (e.g. retraining, new qualifications, aptitude tests and adaptation periods) on each other's professionals, which may needlessly delay and deter migration.

Throughout training, the objective is to develop the knowledge, skills, competence, attitudes and behaviors consistent with specialist level clinical, scientific and professional practice. Clinically, the specialist assesses the appropriate clinical investigations for his/her local population; evaluates how those investigations relate to diagnosis, management and prognosis; and provides the expertise to ensure appropriate application. Scientifically, he/she is able to assess the scope of service need, plan and implement its delivery and ensure a safe and effective working environment. Professionally, the specialist is able to take personal responsibility for his/her actions, working autonomously to take the initiative in complex and unpredictable situations. Additionally, specialists assess, plan, conduct, report, diffuse and adopt their research, development and innovation output. Their clinical leadership training contributes to the evolution of health and healthcare services (Jassam et al., 2018).

\section{References}

Jassam, N., Lake, J., Dabrowska, M., et al., 2018. The European Federation of Clinical Chemistry and Laboratory Medicine Syllabus for Postgraduate Education and Training for Specialists in Laboratory Medicine: Version 5. Clin. Chem. Lab. Med. 56(11), 1846-1863.

Majkić-Singh, N., 2010. Serbian Procedure of Recognition of Professional Qualifications in the Field of Medical Biochemistry. European Education in Laboratory Medicine and Recognition of Professional Qualifications. Warsaw, March 25-27.

Majkić-Singh, N., 2011. Education in medical biochemistry in Serbia. eJIFCC 2011. Available at: http://www.ifcc.org/index.asp?cat=Publications\&scat $=$ eJIFCC \& suba $=V_{0} \_21$ No 2 .

Study Programme: Master of Pharmacy-Medical Biochemist, University of Belgrade, Faculty of Pharmacy, Belgrade. Available at: www.pharmacy.bg.ac.rs.

Maced. Pharm. Bull. 66 (Suppl 1) 3 - 4 (2020) 